\title{
Diverse climate sensitivity of Mediterranean tree-ring width and density
}

\author{
Ulf Büntgen · David Frank • Valerie Trouet • \\ Jan Esper
}

Received: 17 March 2009/Revised: 7 October 2009/Accepted: 4 November 2009/Published online: 22 November 2009

(C) Springer-Verlag 2009

\begin{abstract}
Understanding long-term environmental controls on the formation of tree-ring width (TRW) and maximum latewood density (MXD) is fundamental for evaluating parameter-specific growth characteristics and climate reconstruction skills. This is of particular interest for mid-latitudinal environments where future rates of climate change are expected to be most rapid. Here we present a network of 28 TRW and 21 MXD chronologies from living and relict conifers. Data cover an area from the Atlantic Ocean in the west to the Mediterranean Sea in the east and an altitudinal gradient from 1,000 to 2,500 m asl. Age trends, spatial autocorrelation functions, carry-over effects, variance changes, and climate responses were analyzed for the individual sites and two parameter-specific regional means. Variations in warm season (May-September) temperature mainly control MXD formation ( $r=0.58$ to 0.87 from inter-annual to decadal time-scales), whereas lower TRW sensitivity to temperature remains unstable over space and time.
\end{abstract}

Communicated by T. Buckley.

U. Büntgen $(\varangle) \cdot$ D. Frank $\cdot$ V. Trouet

Swiss Federal Research Institute WSL, Zuercherstrasse 111, 8903 Birmensdorf, Switzerland

e-mail: buentgen@wsl.ch

U. Büntgen · D. Frank

Oeschger Centre for Climate Change Research, Erlachstrasse 9a, 3012 Bern, Switzerland

J. Esper

Department of Geography, Johannes Gutenberg University, Becherweg 21, 55099 Mainz, Germany
Keywords Conifers - Dendroclimatology . Growth responses - Climate reconstructions . Summer temperature

\section{Introduction}

Temperature sensitive tree growth in Europe is mainly restricted to the northern boreal forest and high-elevation sites in the Alps and Carpathian arc, limiting dendroclimatic evidence for the Mediterranean region, which has ironically been defined as a major climate change hotspot (Giorgi 2006), where future rates of temperature increase and precipitation decrease are expected to be most rapid (Gao and Giorgi 2008).

Temperature-controlled formation of tree-ring width (TRW) across Mediterranean environments, if at all existing, is limited to treeline ecotones in the Pyrenees (Schweingruber 1985). Previous studies of sub-alpine forest (Ruiz-Flaño 1988; Rolland and Schueller 1994; Camarero et al. 1998; Tardif et al. 2003; Andreu et al. 2007) and treeline responses to climate change (Camarero and Gutiérrez 2004; Camarero et al. 2005; Wiegand et al. 2006) focused on local scales and living trees, but were never extended to reconstruction purposes. In fact, larger compilations of maximum latewood density (MXD) measurements from relict wood and temporal calibration against different climatic variables are still missing for the Mediterranean region. When screening the International Tree-Ring Data Bank (ITRDB, http://www.ncdc.noaa.gov/ paleo; 11.2008) for twentieth century (1901-2000) low- to mid-latitudinal data $\left(45^{\circ} \mathrm{N}\right.$ to $\left.45^{\circ} \mathrm{S}\right), 99 \mathrm{TRW}$, but no MXD sites are found. These numbers change to 513 and 10 when reducing the period to 1901-1990, calling for a recent update of MXD sites. 
Despite the large effort necessary to develop MXD chronologies (Schweingruber et al. 1978), this parameter is of relevance because of its pronounced climatic fingerprint and skill as an estimator of past climate variability (see references herein). The particular merit of temperature signals preserved in conifer MXD is related to known processes of intra-annual wood formation (Rossi et al. 2006a), and has been reported from numerous sites in the Northern US (e.g., Luckman and Wilson 2005; Szeicz and MacDonald 1995; Wang et al. 2001; Wilson et al. 2007), as well as along a European gradient from Northern Fennoscandia (Briffa et al. 2002), over the Tatra Mountains (Büntgen et al. 2007a), to the Central Alps (Frank and Esper 2005).

Here we present a compilation of existing and newly developed TRW and MXD data from the Pyrenees Mountains. This network covers an area from the Atlantic Ocean in the west to the Mediterranean Sea in the east and an altitudinal gradient from 1,000 to $2,500 \mathrm{~m}$ asl. Site chronologies, as well as parameter-specific regional means are compared with instrumental temperature, precipitation, and drought data. Relationships between climate forcing and tree growth are discussed with a focus on their relevance for ongoing endeavors in reconstructing Mediterranean temperature variability.

\section{Materials and methods}

A dataset of $\sim 163,000$ annually resolved TRW measurements from 28 sites and $\sim 133,000$ MXD measurements from 21 out of these 28 sites in the Pyrenees was compiled (Fig. 1). This compilation represents all available tree-ring chronologies in the area, covers the region $2^{\circ} \mathrm{W}$ to $3^{\circ} \mathrm{E}$ and $42^{\circ}$ to $43^{\circ} \mathrm{N}$, spans elevations from 1,000 to $2,500 \mathrm{~m}$ asl, and includes three conifer species (Abies alba Mill. at eight sites, Pinus sylvestris L. at four sites, and Pinus uncinata Mill. at 16 sites) (Table 1). Pinus uncinata is the dominate species at elevations $>1,600 \mathrm{~m}$ asl. Average site replication is 36 series, but represents a large range from 8 to 203 series (Fig. 2). Start and end dates of the site records range from 1260 to 1935 and 1977 to 2005 , respectively (after truncation at $<5$ series). While all sites contain samples from living trees, dry-dead material derives from five Pinus uncinata sites (Table 1).

TRW samples were processed following standard techniques outlined in Stokes and Smiley (1968). MXD was measured via a WALESCH 2003 X-ray densitometer with a resolution of $0.01 \mathrm{~mm}$, and brightness variations transferred into $\mathrm{g} / \mathrm{cm}^{3}$ using a calibration wedge (Eschbach et al. 1995). Relationships between the absolute (volume and weight) and radiographic (X-ray) wood density (considering different species) were employed as correction factors.

To remove non-climatic age trends from the raw measurements, TRW and MXD series were detrended (standardized) using cubic smoothing splines with a 50\% frequency-response cutoff equal to 300 years (Cook and Peters 1981). Indices were calculated as ratios (and as residuals after power transformation) from the estimated growth curves and averaged using a bi-weight robust mean (Cook and Peters 1997). Since such individual detrending eliminates wavelengths longer than the mean series length (Cook et al. 1995), the regional curve standardization method (RCS, Esper et al. 2003) was additionally applied (to the raw or power transformed values) to retain lower
Fig. 1 Location of the 28 TRW sites. Filled circles indicate the 21 sites from where additional MXD measurements exist. Bottom panel indicates elevations of the sampling sites

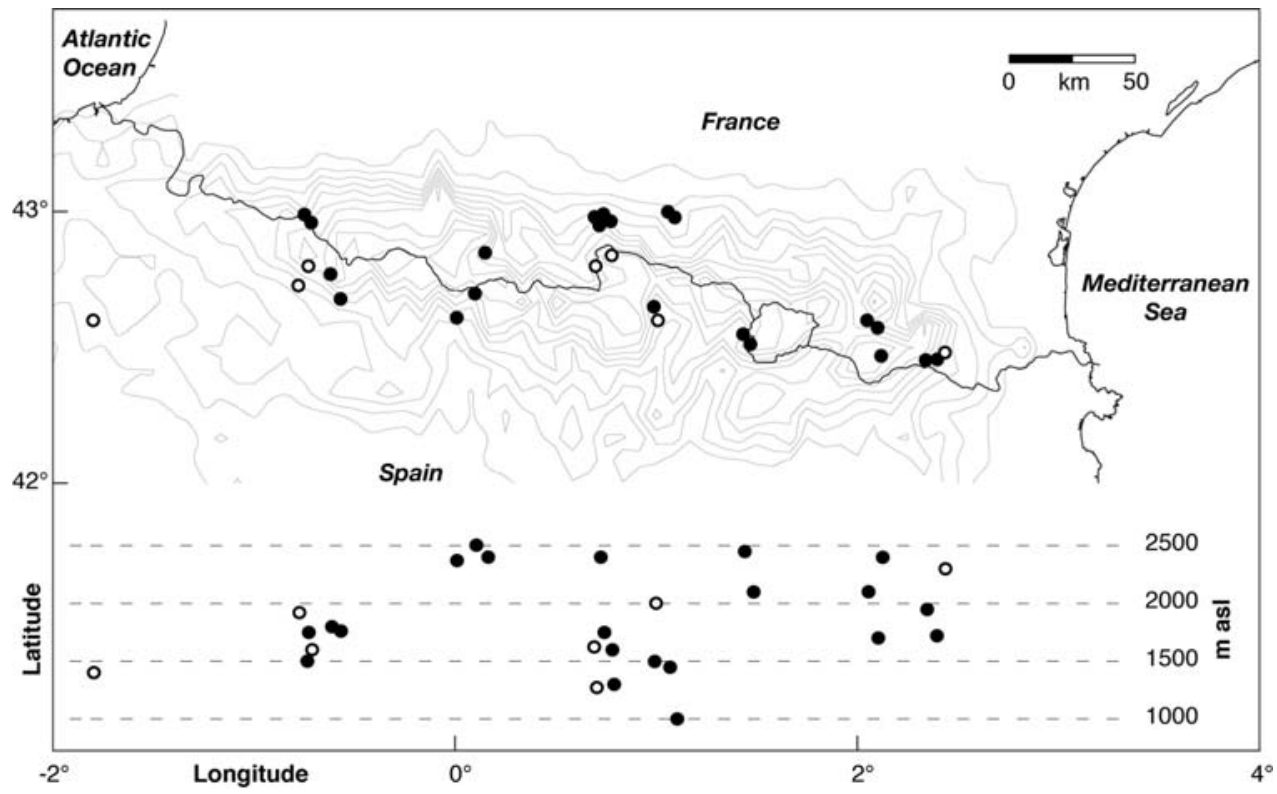


Table 1 Characteristics of the site chronologies, with MXD site numbers and mean density values indicated in bold

\begin{tabular}{|c|c|c|c|c|c|c|c|c|c|c|}
\hline Site & Lon (-E) & Lat $(\mathrm{N})$ & Elevation (m asl) & Species & Series & Rings & Start ( $\geq 5$ series $)$ & End & MSL & AGR \\
\hline 1 & 1.80 & 42.60 & 1,400 & PISY & 28 & 1,820 & 1933 (1935) & 2005 & 65 & 2.89 \\
\hline $2(3)$ & 0.70 & 42.40 & 1,870 & PIUN & 18 & 3,168 & 1609 (1748) & 1977 & 176 & $1.09(\mathbf{0 . 8 0})$ \\
\hline 4 & 0.47 & 42.44 & 1,920 & PISY & 29 & 4,582 & $1752(1780)$ & 1985 & 158 & 1.67 \\
\hline $5(6)$ & 0.45 & 42.59 & 1,500 & $\mathrm{ABAL}$ & 20 & 3,040 & 1743 (1795) & 1977 & 152 & $1.02(\mathbf{0 . 8 3})$ \\
\hline $7(8)$ & 0.44 & 42.58 & 1,750 & PIUN & 20 & 4,220 & 1659 (1702) & 1977 & 211 & $0.91(\mathbf{0 . 7 1})$ \\
\hline 9 & 0.44 & 42.48 & 1,600 & PIUN & 32 & 4,640 & $1829(1843)$ & 2005 & 145 & 1.23 \\
\hline $10(\mathbf{1 1})$ & 0.37 & 42.46 & 1,800 & $\mathrm{ABAL}$ & 26 & 4,134 & 1784 (1796) & 1977 & 159 & $1.46(\mathbf{0 . 8 2})$ \\
\hline 12 (13) & 0.34 & 42.41 & 1,760 & PIUN & 20 & 2,840 & 1808 (1819) & 1977 & 142 & $1.50(\mathbf{0 . 8 2})$ \\
\hline 14 & 0.13 & 42.30 & 2,000 & PIUN & 40 & 6,560 & $1811(1816)$ & 1996 & 164 & 0.94 \\
\hline $15(\mathbf{1 6})$ & -0.06 & 42.42 & 2,500 & PIUN & 58 & 13,572 & 1499 (1517) & 2005 & 234 & $0.75(\mathbf{0 . 6 6})$ \\
\hline 17 (18) & -0.09 & 42.51 & 2,400 & PIUN & 82 & 14,022 & 1324 (1669) & 2005 & 171 & $0.96(\mathbf{0 . 6 7})$ \\
\hline 19 & -0.42 & 42.48 & 1,625 & PISY & 30 & 5,880 & 1605 (1703) & 1985 & 196 & 1.19 \\
\hline 20 & -0.47 & 42.50 & 1,275 & PISY & 8 & 1,600 & 1696 (1805) & 1985 & 200 & 1.31 \\
\hline $21(\mathbf{2 2})$ & -0.59 & 42.38 & 2,400 & PIUN & 203 & 41,615 & 924 (1260) & 2005 & 205 & $0.82(\mathbf{0 . 6 3})$ \\
\hline $23(\mathbf{2 4})$ & -0.70 & 42.97 & 1,750 & PIUN & 28 & 4,200 & 1713 (1763) & 1995 & 150 & $1.25(\mathbf{0 . 6 4 )}$ \\
\hline $25(\mathbf{2 6})$ & -0.71 & 42.98 & 1,600 & PIUN & 26 & 3,874 & 1708 (1810) & 1995 & 149 & $1.18(\mathbf{0 . 6 4 )}$ \\
\hline $27(\mathbf{2 8})$ & -0.74 & 43.00 & 1,300 & $\mathrm{ABAL}$ & 11 & 1,155 & 1773 (1908) & 1994 & 105 & $2.40(\mathbf{0 . 7 5})$ \\
\hline $29(\mathbf{3 0})$ & -0.75 & 42.99 & 1,500 & $\mathrm{ABAL}$ & 8 & 768 & 1846 (1909) & 1994 & 96 & $1.40(\mathbf{0 . 7 4})$ \\
\hline 31 (32) & -1.06 & 43.00 & 1,450 & $\mathrm{ABAL}$ & 14 & 1,232 & 1819 (1878) & 1994 & 88 & $1.80(\mathbf{0 . 7 3})$ \\
\hline $33(\mathbf{3 4})$ & -1.06 & 43.00 & 1,000 & $\mathrm{ABAL}$ & 10 & 720 & 1841 (1928) & 1994 & 72 & $2.86(\mathbf{0 . 7 7})$ \\
\hline 35 (36) & -1.25 & 42.32 & 2,450 & PIUN & 42 & 8,862 & 1377 (1534) & 2005 & 211 & $0.72(\mathbf{0 . 6 0})$ \\
\hline 37 (38) & -1.30 & 42.32 & 2,100 & PIUN & 24 & 2,640 & 1793 (1839) & 1977 & 110 & $1.69(\mathbf{0 . 7 5})$ \\
\hline $39(\mathbf{4 0})$ & -2.03 & 42.36 & 2,100 & PIUN & 22 & 3,718 & 1769 (1783) & 1977 & 169 & $1.23(\mathbf{0 . 7 1})$ \\
\hline $41(42)$ & -2.04 & 42.36 & 1,700 & $\mathrm{ABAL}$ & 20 & 3,400 & $1742(1781)$ & 1977 & 170 & $1.00(\mathbf{0 . 8 8})$ \\
\hline $43(44)$ & -2.07 & 42.28 & 2,400 & PIUN & 84 & 10,500 & 1736 (1749) & 2004 & 125 & $1.18(\mathbf{0 . 6 9 )}$ \\
\hline 45 (46) & -2.23 & 42.27 & 1,950 & PIUN & 20 & 2,400 & 1839 (1848) & 1977 & 120 & $1.72(\mathbf{0 . 7 4})$ \\
\hline 47 (48) & -2.24 & 42.28 & 1,720 & $\mathrm{ABAL}$ & 24 & 2,832 & $1831(1840)$ & 1977 & 118 & $2.04(\mathbf{0 . 8 7})$ \\
\hline 49 & -2.25 & 42.29 & 2,300 & PIUN & 42 & 4,788 & 1798 (1862) & 2005 & 114 & 1.43 \\
\hline
\end{tabular}

$M S L$ mean segment length (years), $A G R$ average growth rate with TRW in $\mathrm{mm}$ and MXD in $\mathrm{g} / \mathrm{cm}^{3}$ (MXD measurements = bold)

1 Pamplona, 2 Turbon Ordessa, 4 Viella Monte Vilach, 5 Arette Col St. Martin, 7 Pic d' Anie, 9 Val de Hecho, 10 Pic Aubas, 12 Las Blancas Jaca, 14 Sant Maurici, 15 Sobrestivo, 17 Lac d'Aumer, 19 Hecho Puerto de Acher, 20 Anso Zuriza, 21 Gerber, 23 Bois de Girabe Catazar high, 25 Bois de Girabe Catazarjow, 27 Bois de Guillers, 29 L'Arre de Bas, 31 Crete d'Uthurkokotcha, 33 Pic de Bizkarze, 35 Port de Cabus, 37 Bosque de Rabassa, 39 Roc de Perches Blancas, 41 Formi-gueres, 43 Eyne, 45 Llipodere, 47 Miraules Refuge, 49 Pic de sept Hommes (sites with MXD measurements = bold)

frequency information (using ratios or residuals). Series were first aligned by cambial age, a mean of these agealigned series calculated, and this mean smoothed using a cubic spline of $10 \%$ the series length. The resulting timeseries is termed regional curve (RC) and used for detrending, i.e., deviations of the individual measurements from the RC were calculated as ratios (and as residuals after power transformation). Dimensionless indices were then dated back to calendar years, and averaged to form a chronology. The variance in the mean chronology was stabilized using a time dependent '100-year moving window' approach for adjusting temporal changes in both, sample replication and inter-series correlation (Frank et al. 2007b). Final chronologies were truncated at $<5$ series. Inter-series correlation
(Rbar) and the expressed population signal (EPS) were calculated for 30-year windows lagged by 15 years along the time-series to assess their signal strength (Wigley et al. 1984). Mean EPS of the 28 TRW (21 MXD) chronologies is $0.85(0.85)$ and ranges from 0.62 to $0.96(0.68-0.96)$. Mean Rbar of the TRW (MXD) data is 0.30 (0.34).

Varimax rotated principal component analysis (PCA, Richman 1986) was performed to detect chronology subsets of 'optimized' signal coherency within and between the two tree-ring parameters. Correlations as a function of distance between sites revealed patterns of spatial autocorrelation.

Temperature means, precipitation sums (CRUTS2.1, Mitchell and Jones 2005), and the self-calibrated Palmer Drought Severity Index (scPDSI, van der Schrier et al. 2006) 
Fig. 2 Distribution of 989 core samples that contain 164,000 annual TRW measurements from 28 sites. Data are ordered from west (bottom) to east (top). The 21 sites with additional 134,000 MXD measurements are shown in black

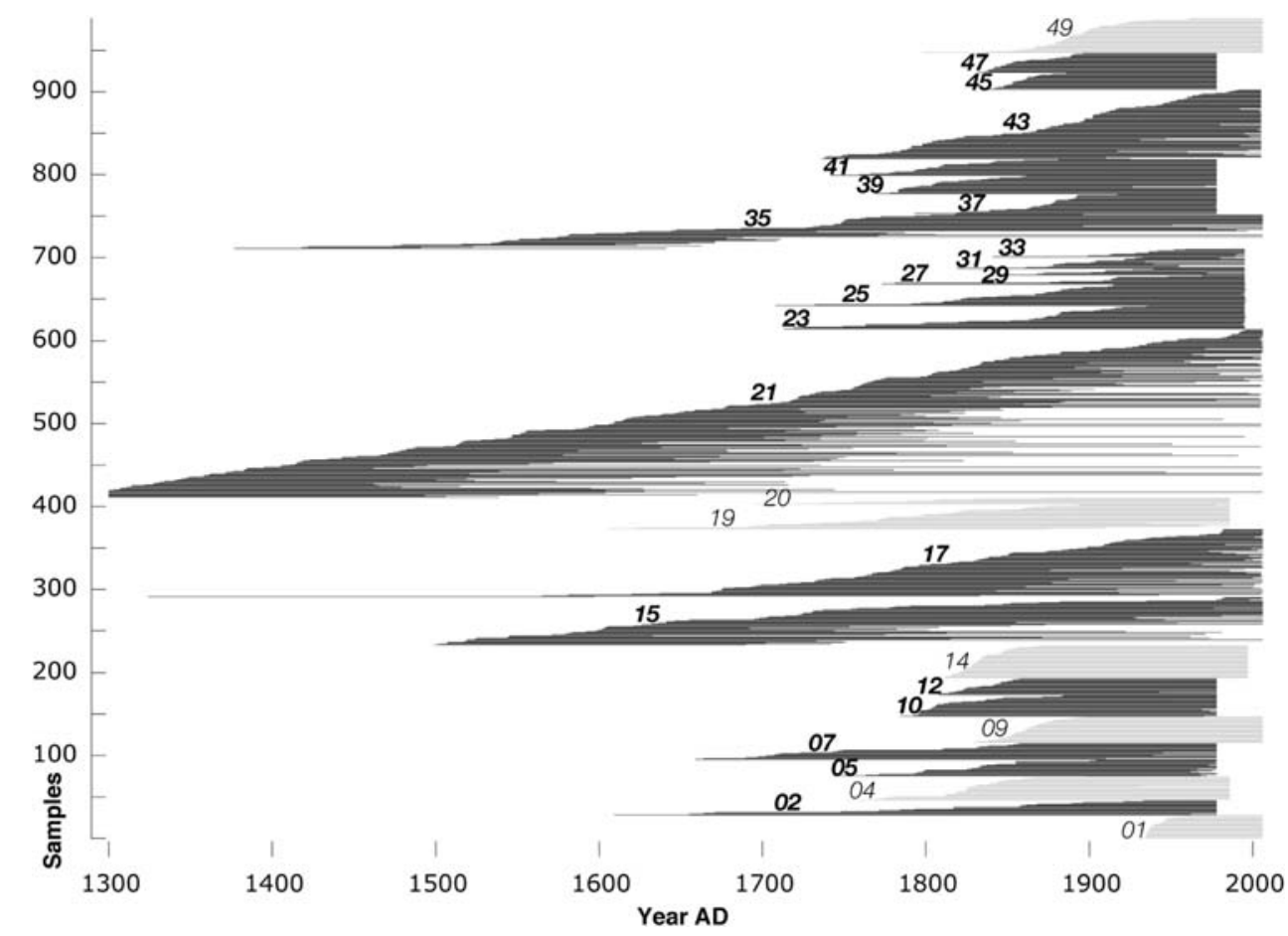

were utilized to determine-via correlation analysis-the network's dominant climatic controls (see Fig. 3 for comparison of the climatic parameters). Meteorological data (1901-2002) were averaged over $48\left(0.5^{\circ} \times 0.5^{\circ}\right)$ grid- boxes covering the greater Pyrenees region $\left(2.25^{\circ} \mathrm{W}\right.$ to $3.25^{\circ} \mathrm{E}$ and $41.75^{\circ} \mathrm{N}$ to $43.25^{\circ} \mathrm{N}$ ). Correlation significance levels were conservatively corrected for lag-1 autocorrelation.
Fig. 3 a Unfiltered and 20 years low-pass filtered summer (June-August) temperature, precipitation and PDSI anomalies (wrt. 19611990). b 31 years moving standard deviations of the three records scaled to have means of zero and standard deviations of one. Inset denotes correlation (1901-2002) between the unfiltered (upper-right correlation coefficients) and 20 years low-pass filtered (lower-left correlation coefficients) climatic timeseries

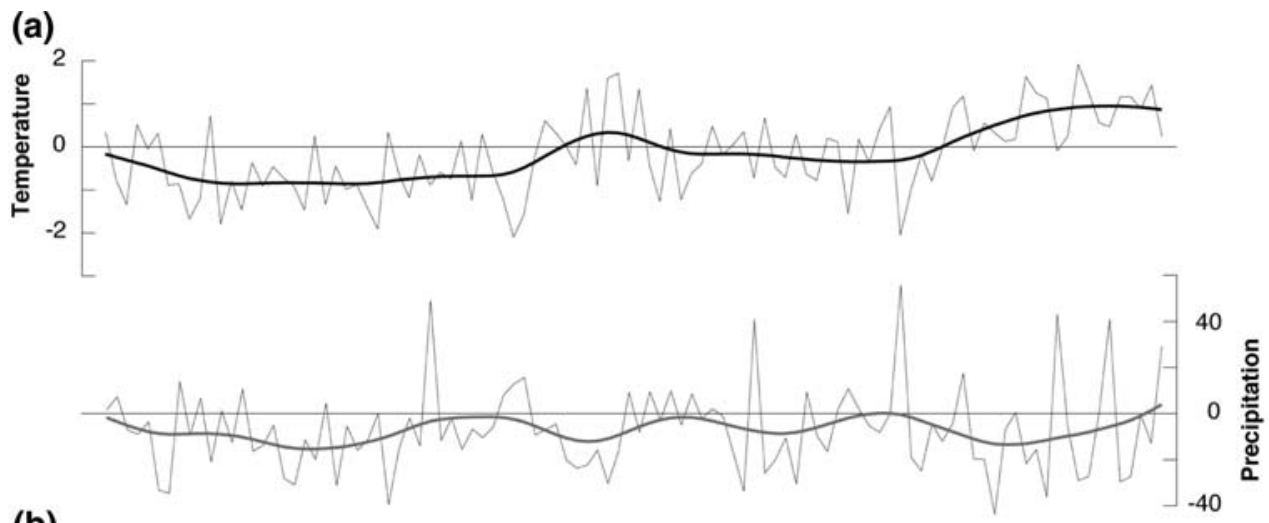

(b)

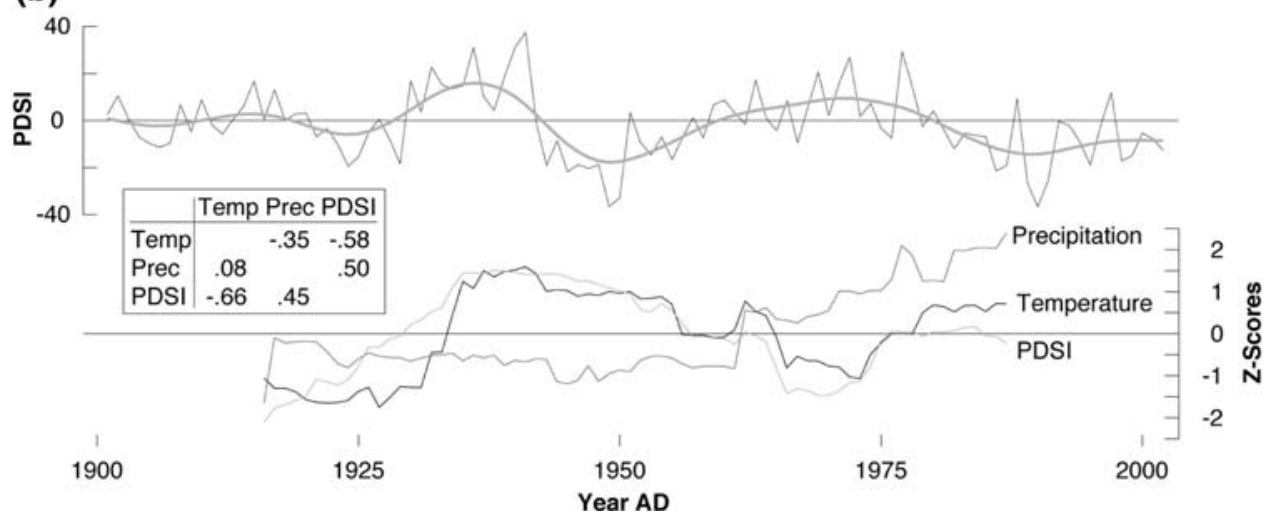




\section{Results}

Site chronologies

Mean segment length (i.e., average number of rings per core or disc sample) of the 989 TRW series is 166 and individual segment lengths range from 11 to 732 years (Table 1). Mean segment length of the $780 \mathrm{MXD}$ series is 172 years. Average TRW is $1.2 \mathrm{~mm} /$ year and average MXD $0.69 \mathrm{~g} / \mathrm{cm}^{3}$ (Fig. 4, inset). After aligning the raw measurement series of all 28 TRW and 21 MXD sites by cambial (i.e., biological) age, mean 'regional' curves (RCs) emphasize common age trends in annual diameter and density (Fig. 4). While TRW portrays a nearly exponential decline with increasing tree age, a more linear decrease is reflected by MXD. Mean lag-1 autocorrelation of the TRW and MXD site chronologies is 0.62 and 0.12 , respectively, indicating higher carry-over effects in radial increment compared to cell wall thickening.

Rotated PCA (1935-1977) of the 49 chronologies separates (low) TRW from (high) MXD loadings (not shown).
Nineteen out of 21 MXD chronologies have high loadings on the first PC axis that explains $32 \%$ of the network's variance. The second PC axis explains $21 \%$ of variance and 13 out of 28 TRW chronologies have high loadings on this axis. Highest loadings of the remaining 15 TRW chronologies are distributed across the next seven PCs axis. No robust grouping per species or elevation is found. Parameter-specific correlations as a function of distance between sites reveal a stronger spatial coherency for MXD than TRW (Fig. 5). The mean correlation of all 210 MXD chronology-pairs is 0.58 (STDEV 0.17), but decreases to 0.25 (STDEV 0.27) when using the corresponding TRW data. The lower mean values, as well as faster declining correlations with distance demonstrate a reduced degree of common variance between the TRW sites. In contrast, MXD sites show enhanced spatial coherency with a different signal-to-noise ratio.

Correlation analysis of the site chronologies (using either ratios or residuals after power-transformation for index calculation; Fig. 6) with instrumental temperature, precipitation, and drought data confirms that parameter-specific
Fig. 4 Site (gray) and average (black) regional curves (RCs) of the (a) $28 \mathrm{TRW}$ and (b) 21 MXD sites after truncation $<5$ series. Scatter plots describe the relationship between average growth rate and segment length of all 989 TRW and 780 MXD measurement series
Fig. 5 Correlation analysis of the 21 TRW (left) and MXD (right) chronologies as a function of distance between sites. Lines indicate linear trends of the spatial correlation based on all (210) possible pairings
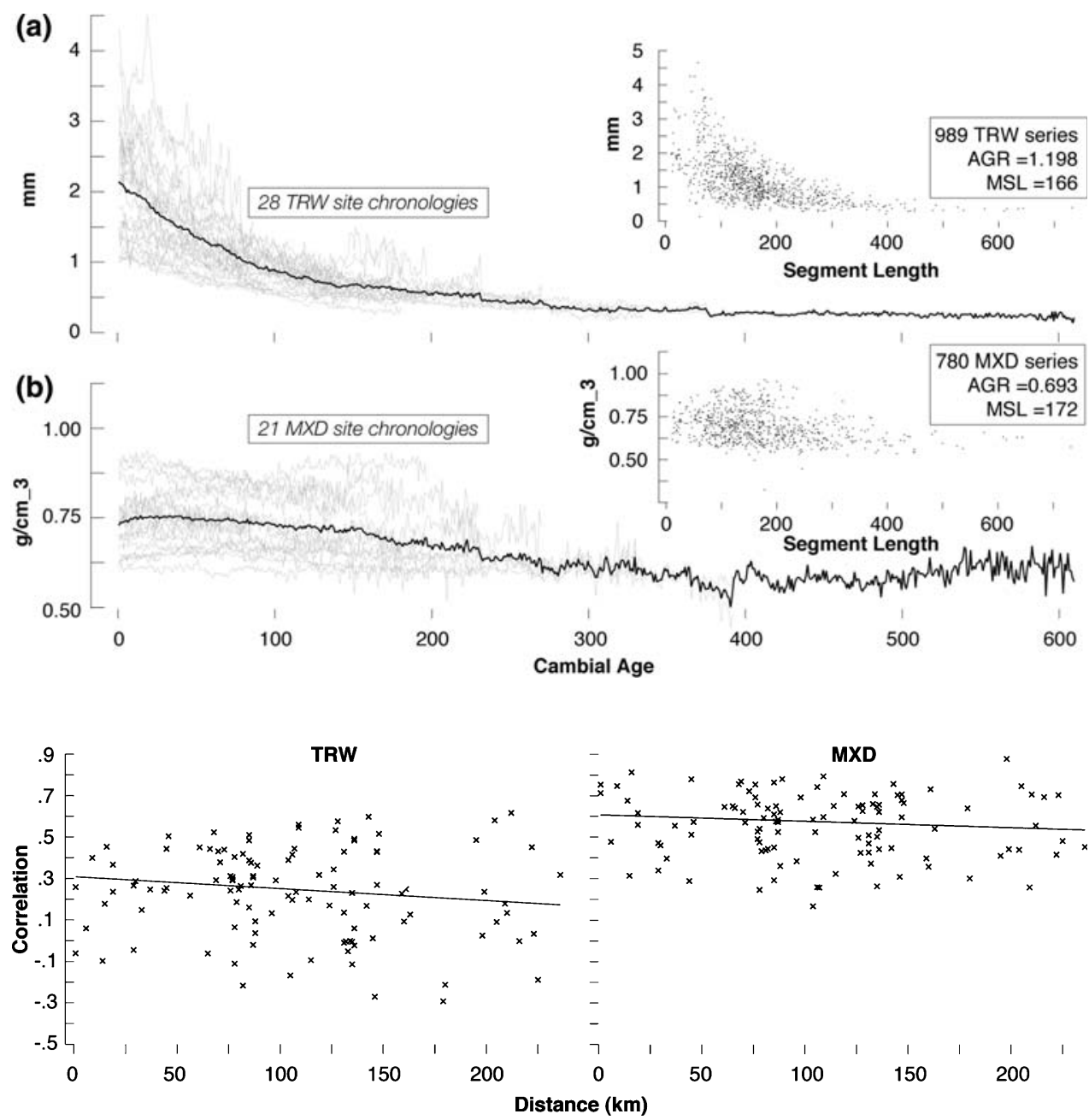
Fig. 6 Shape of the 28 TRW (gray) and 21 MXD (black) chronologies after RCS detrending using ratios (left) or residuals after power transformation (right). Timeseries have been normalized over their individual length

Fig. 7 Correlation coefficients between the TRW and MXD (gray horizontal shadings) site chronologies (after 300 years spline and RCS detrending with and without powertransformation) and summer (May-September) a temperature, b precipitation, and $\mathbf{c}$ drought data computed over the common period 19011977
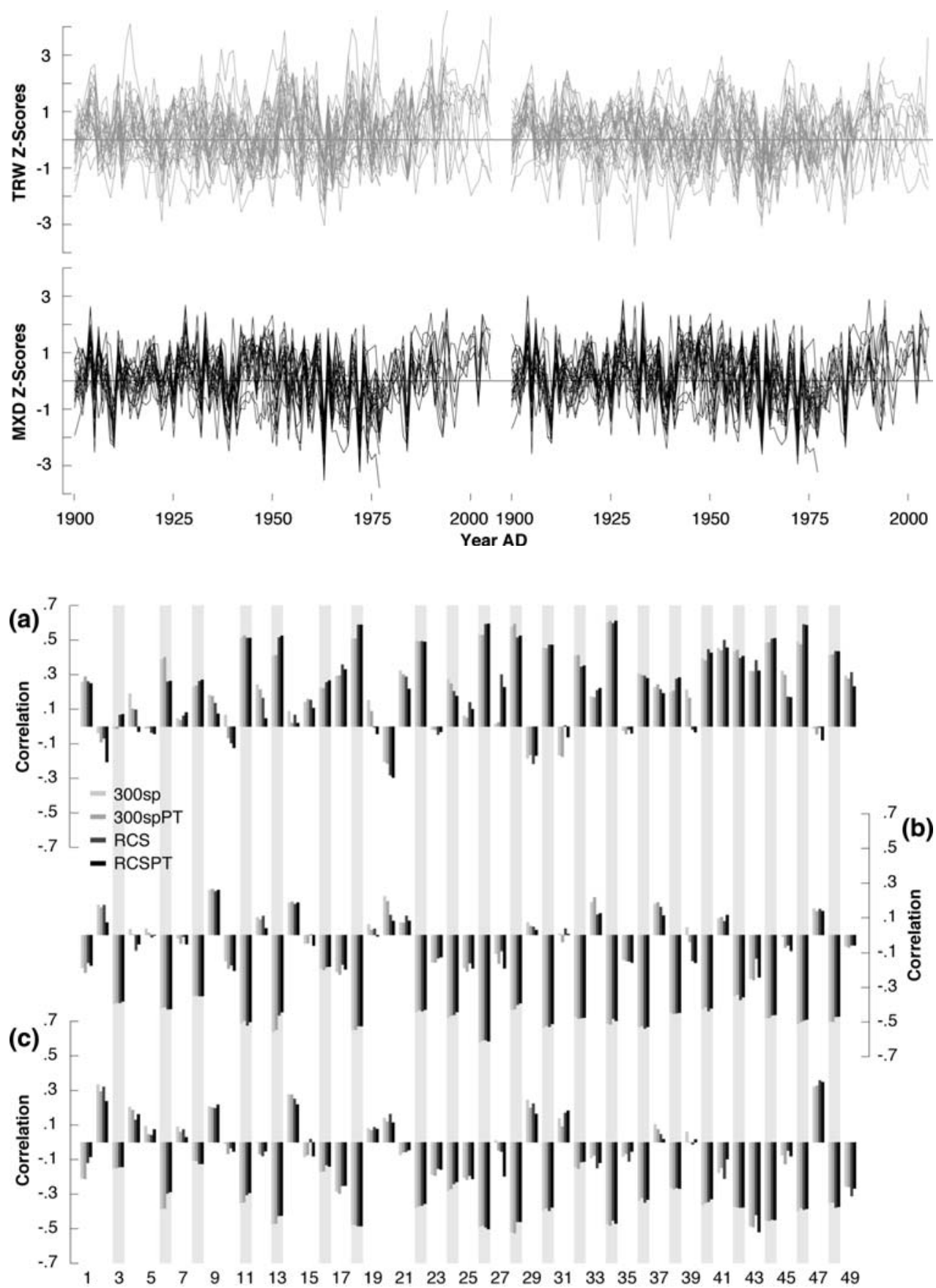

differences are most important (Fig. 7). Significant correlation $(p<0.01)$ between the chronologies and warm season temperature is much more frequent for MXD than TRW: 16 out of 21 MXD sites correlate significantly positive with warm-season temperature. In contrast, seven out of $28 \mathrm{TRW}$ chronologies correlate significantly positive with summer temperature. Overall lower correlations are recorded for precipitation totals, with only 11 chronologies (none of them MXD) revealing significantly positive relationships. Correlations with the scPDSI are mostly non-significant for both parameters. Species-specific and geographic (considering elevation and location) effects on the climate sensitivity of MXD are of minor importance.

Regional chronologies

Raw measurement series of the 21 sites from where both parameters exist were separately compiled to create regional TRW and MXD chronologies likely to be representative for the greater Pyrenees region (Fig. 8a). The average elevation of these sites (eight sites Abies alba and 13 sites Pinus uncinata) is $1,860 \mathrm{~m}$ asl and their average 
Fig. 8 Sample replication of a the 21 chronologies from where TRW and MXD measurements exist. b Inter-site correlation (site Rbar) of the MXD and TRW chronologies. $\mathbf{c}$ MXD and d TRW RCS chronologies after the application of various variance adjustment steps (gray). Final records based on running Rbar adjustments (VARCS) shown in black. Smoothed curves are the VARCS chronologies after 60 years low-pass filtering. Bottom of panel $\mathbf{c}$ and $\mathbf{d}$ shows 31 years moving standard deviations highlighting the effect of the various variance adjustments applied. Horizontal thin lines indicate the mean STDEV of the VARCS chronologies
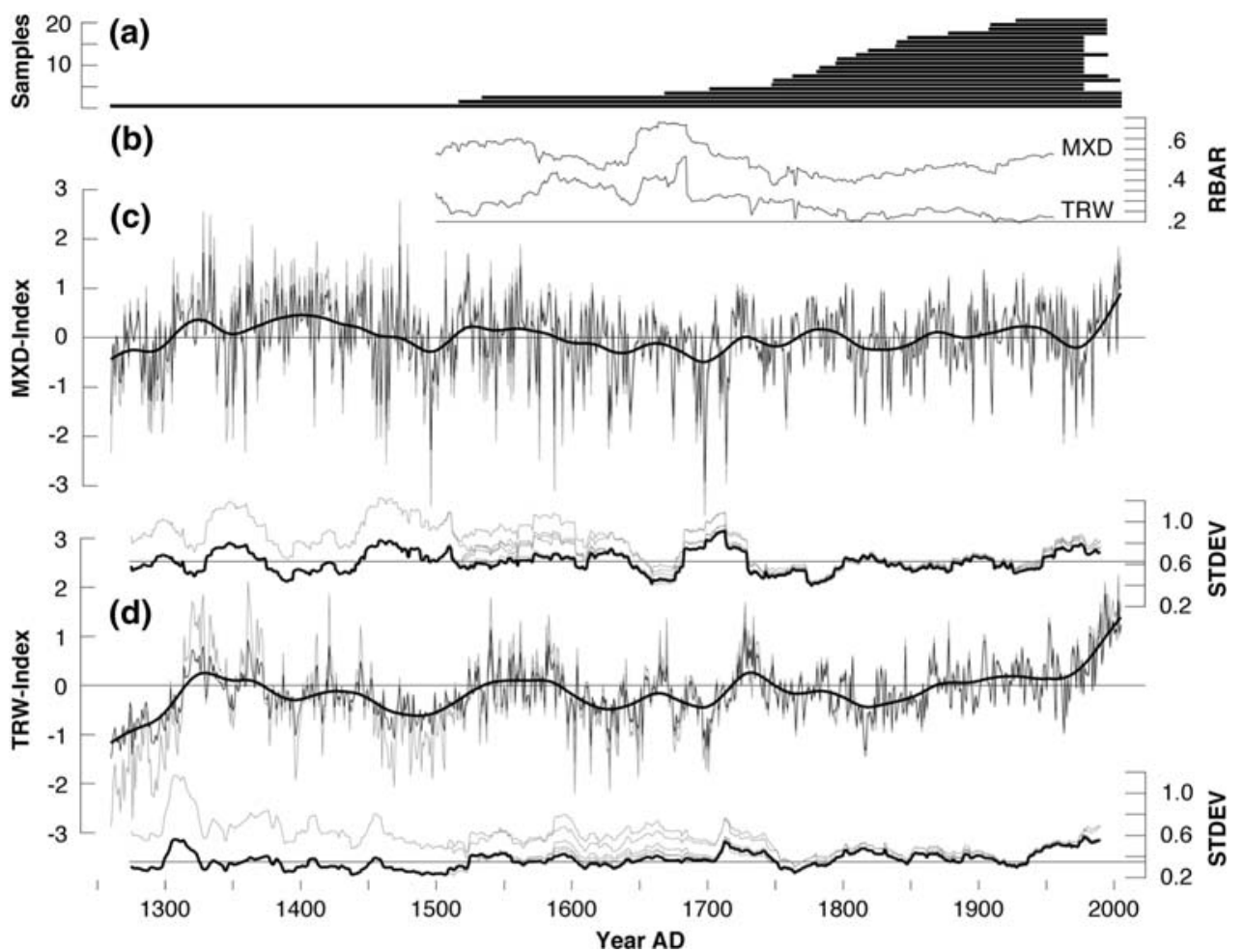

location is at $42^{\circ} 57^{\prime} \mathrm{N}, 0^{\circ} 79^{\prime} \mathrm{E}$. Correlations between the individual site chronologies are consistently higher for MXD than for TRW (Fig. 8b). Running Rbar values of the parameter-specific mean records denote similar patterns for TRW and MXD, with overall higher values during earlier periods until $\sim 1700$, followed by lower internal coherency from $\sim 1750$ to 1850 , and increasing values again towards present. The parameter-specific variance adjusted RCS chronologies (VARCS, AD 1260-2005) reflect interannual to multi-centennial scale variability (Fig. 8c, d). The MXD-based VARCS record retains low index values during the late thirteenth century, followed by a century of higher values, and again low values from $\sim 1600$ to 1750 . MXD shows a positive trend over the past $\sim 300$ years with some decadal fluctuations such as the early 1800s and 1960-1970s superimposed. The TRW-based VARCS record generally reveals more decadal-scale variability, but the main features are similar to those mirrored by the MXD-based time-series. Low index values occurred during the late thirteenth century, $\sim 1500$, the seventeenth and the early nineteenth century. Above average TRW values appeared from $\sim 1300$ to 1360,1540 to 1590 , at 1730 , and again from 1870 to present.

The key difference between the parameter-specific VARCS records is a 'redder' character of TRW compared to a 'whiter' spectrum of MXD. That is, the MXD chronology contains enhanced high-frequency variability compared to the TRW data that consist of more lowfrequency information. Lag-1 autocorrelation of the MXD record is equal to zero, but 0.48 for TRW (1901-2002). In comparison, persistence in warm season precipitation, temperature, and scPDSI (May-September) is zero, 0.34, and 0.56 , respectively. These differences in time-series characteristics are best expressed in their power spectra (Fig. 9a). Significant power peaks of the MXD data on the inter-annual scale are at $\sim 2.2$ and $\sim 2.4$ years. On decadal to centennial time-scales MXD power peaks are significant at $\sim 21$ and 51-72 years. Again, the TRW data indicate less inter-annual but more long-term ( $>85$ years) power.

Correlations between the MXD and TRW records computed over the maximum 1260-2005 and two split periods (1260-1632/1633-2005) depict stronger coherency over the post 1633 period. While the unfiltered chronologies correlate at 0.32 and 0.45 over the early and late period, respectively, correlations increase to $0.52-0.72$ and 0.59-0.77 after 10-60 years low-pass filtering. Correlations obtained from the low-passed records computed over the full period range below those from the two split periods. After 10-60 year high-pass filtering of the chronologies, correlations decrease to $0.15-0.20$ and $0.34-0.36$ for the early and late period, respectively. Most significant correlation differences between the early/late split periods are revealed from the band-passed time-series. While correlation over the early period between the TRW and MXD records after 10-20 year band-pass filtering is zero, highest correlation of 0.79 is obtained after 40-60 year band-pass filtering and the late period. This harmonic mid-frequency 
Fig. 9 a Multi-taper (MTM) power spectrum of the unfiltered VARCS MXD (black) and TRW (gray) chronologies (1633-2005). Thin curves are 95\% confidence levels. b Comparison between the 40-60 years band-pass filtered VARCS MXD and TRW chronologies
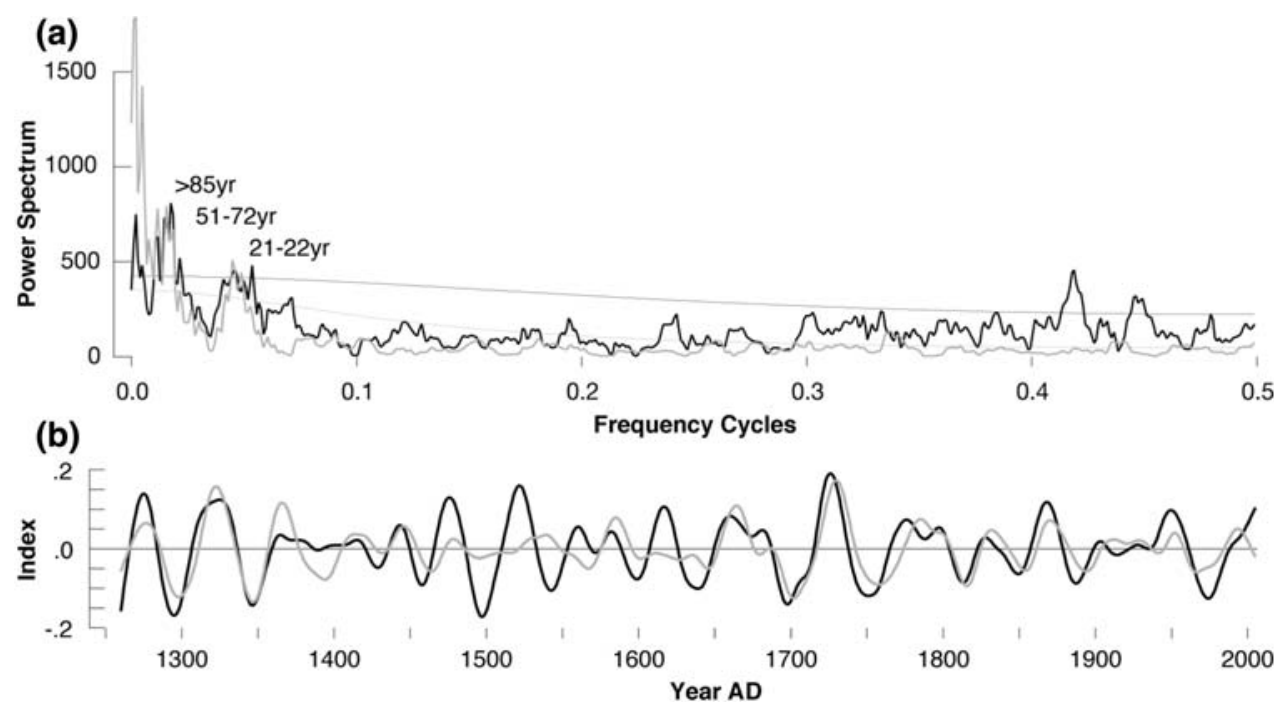

variability is illustrated in Fig. 9b. In-phase swings of the two parameter-specific VARCS chronologies are most distinct between 1260-1360, 1450, and from 1650 to present. Note that some recent divergence between decreasing TRW and increasing MXD data is most likely inflated by the smoothing applied. In contrast, more realistic offset is evident during the fifteenth to sixteenth century, when either differing variance (e.g., 1400) or opposing trends (e.g., 1540) occurred.

Correlation coefficients of regional mean records with monthly temperature, precipitation, and scPDSI grid-box data show parameter-specific differences that are most pronounced during the first half of the twentieth century (Fig. 10). Significant $(p<0.01)$ correlations of the
Fig. 10 Growth responses of the VARCS TRW (left) and MXD (right) chronologies computed against monthly values of the previous and current year, plus various seasonal means using a temperature, $\mathbf{b}$ precipitation and c scPDSI data over the full (1901-2002) and two split periods (1901-1951/19522002). Horizontal lines denote 99.9\% confidence levels, and the vertical shadings highlight the May-September window of highest temperature correlation

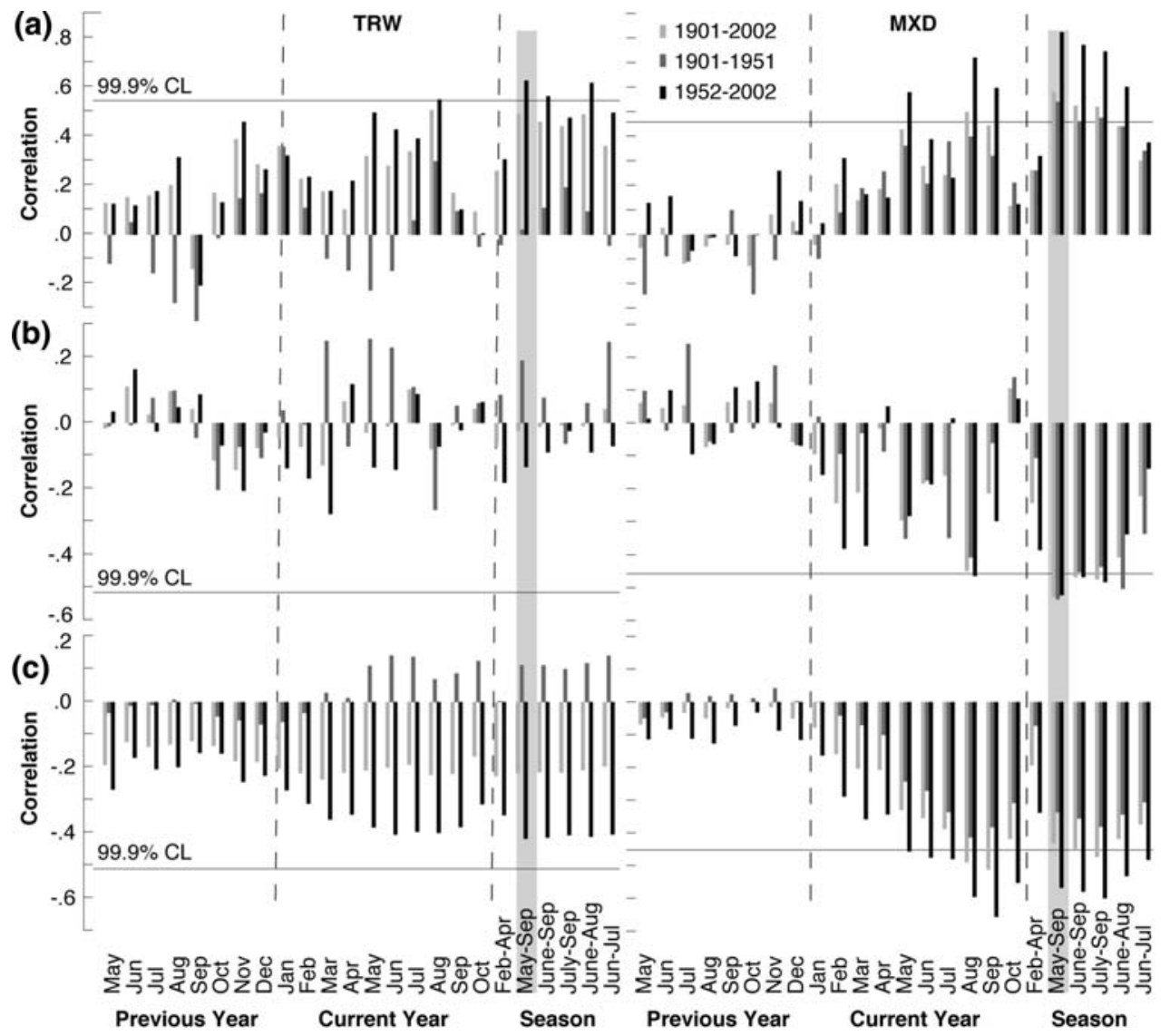


VARCS MXD record with temperature are found for May, August, and September, with highest correlations obtained for seasonal means that consider monthly values from May to September (Fig. 10a). Significant correlations of the VARCS TRW record with monthly temperatures are found for August and the seasonal means of May-September, June-September, and June-August. It is noteworthy that both parameters show lower correlations during the height of the summer (June, July), than during the surrounding months or the season as a whole. The VARCS MXD chronology correlates negatively, though not significantly, with late summer scPDSI values (monthly means of August and September), and with a number of warm season precipitation and scPDSI means (Fig. 10b, c). The VARCS TRW chronology, on the other hand, shows non-significant correlations with either precipitation or drought. Climatic conditions of the year previous to ring formation did not influence either MXD or TRW. Also interesting is the fact, that the VARCS TRW time-series did not show significant correlations with climate during the first half of the 20th century.

For a more frequency-dependent understanding of the detected growth responses to temperature, both proxy (MXD and TRW VARCS) and target (May-September temperature) time-series were low-, high-, and band-pass filtered (Fig. 11). Highest correlation of 0.90-0.97 results from low-pass filtering the MXD data (1952-2002). Overall lower correlations of $0.31-0.44$ result from the low-passed MXD time-series when using the full 19012002 period of overlap. Correlations between the high-pass filtered MXD and temperature data are $\sim 0.80,0.68$, and 0.57 when computing over the late, full, and early period, respectively. No effect of the filter length is found in the higher frequency domain. While only small differences between lowest and highest correlations are found within either the low- or high-pass filtered data, significant variation between lowest and highest correlations is found after band-pass filtering. Lowest correlation of 0.51 and highest correlation of 0.96 were obtained from the 10-20 and 40-60 years band-passed time-series (1952-2002), respectively. Even though late 20th century (1952-2002) TRW shows similar high correlation (0.98) in the lowest frequency domain (after 60 year low-pass filtering), an overall less stable relationship between the TRW parameter and higher frequency climate variability is obvious. In line with the correlation results achieved from the MXD parameter, generally weaker TRW/temperature coherency was derived for the first half of the 20th century.

Spatial correlation between the VARCS records and European May-September temperature describes instable relationships for TRW. No variance is explained before 1951 and only little variance is explained afterwards (Fig. 12a). In contrast, MXD explains a significant higher amount of variance over the entire 20th century and over most of southwestern Europe (Fig. 12b). For an independent evaluation, similar maps were computed using instrumental measurements from the Pic du Midi mountain observatory - this station is not included in the CRUTS2.1 grid (Fig. 12c). Spatiotemporal correlation clusters for the Pic du Midi and MXD records are quite similar. The Pyrenees, European Alps, Italian Apennine, and African Atlas Mountains are all subjected to similar synoptic patterns of climate variability.

\section{Discussion}

Age trends, wood formation, and growth characteristics

While age trends of the analyzed TRW series mainly depend on geometrical reasons (e.g., Fritts 1976), more subtle and less-well understood physiological processes appear to be responsible for the age trends in MXD (Schweingruber et al. 1978). Two possible hypothesis can
Fig. 11 Growth responses of the VARCS TRW and MXD chronologies to May-September mean temperatures over the full (1901-2002) and two split periods (1901-1951 and 19522002). Correlations were computed using unfiltered, lowand high-pass filtered (10, 20, $30,40,50$, and 60 years), and band-pass filtered (10-20, 10-30, 10-40, 10-50, 10-60, 20-40, 30-50, 40-60, and 20-60 years) data
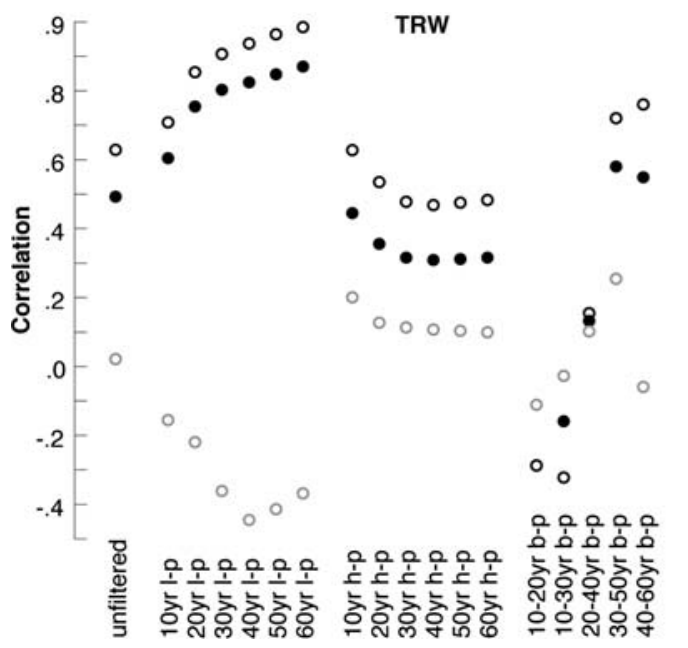

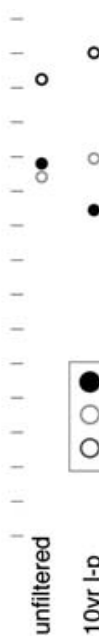

$\circ \circ 0 \circ \circ \circ$
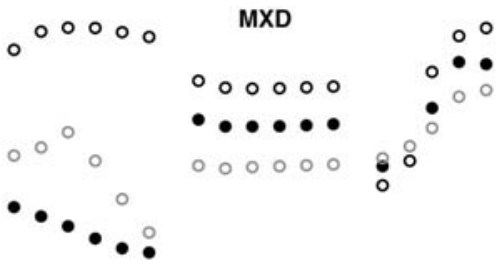

1901-2002

1901-1951

1952-2002

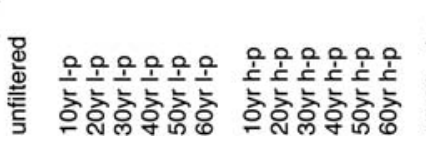

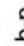
운우울우울 क्? फ़् 
Fig. 12 Spatial correlations between $0.5^{\circ} \times 0.5^{\circ}$ grid-box May-September temperatures (CRU TS2.1) and the a TRW, b MXD VARCS time-series, and c May-September temperatures from the Pic du Midi $\left(2862 \mathrm{~m}\right.$ asl, $43^{\circ} 04^{\prime} \mathrm{N}$, $0^{\circ} 09^{\prime} \mathrm{E}, \mathrm{AD}$ 1882-2003), computed over the full and two split periods

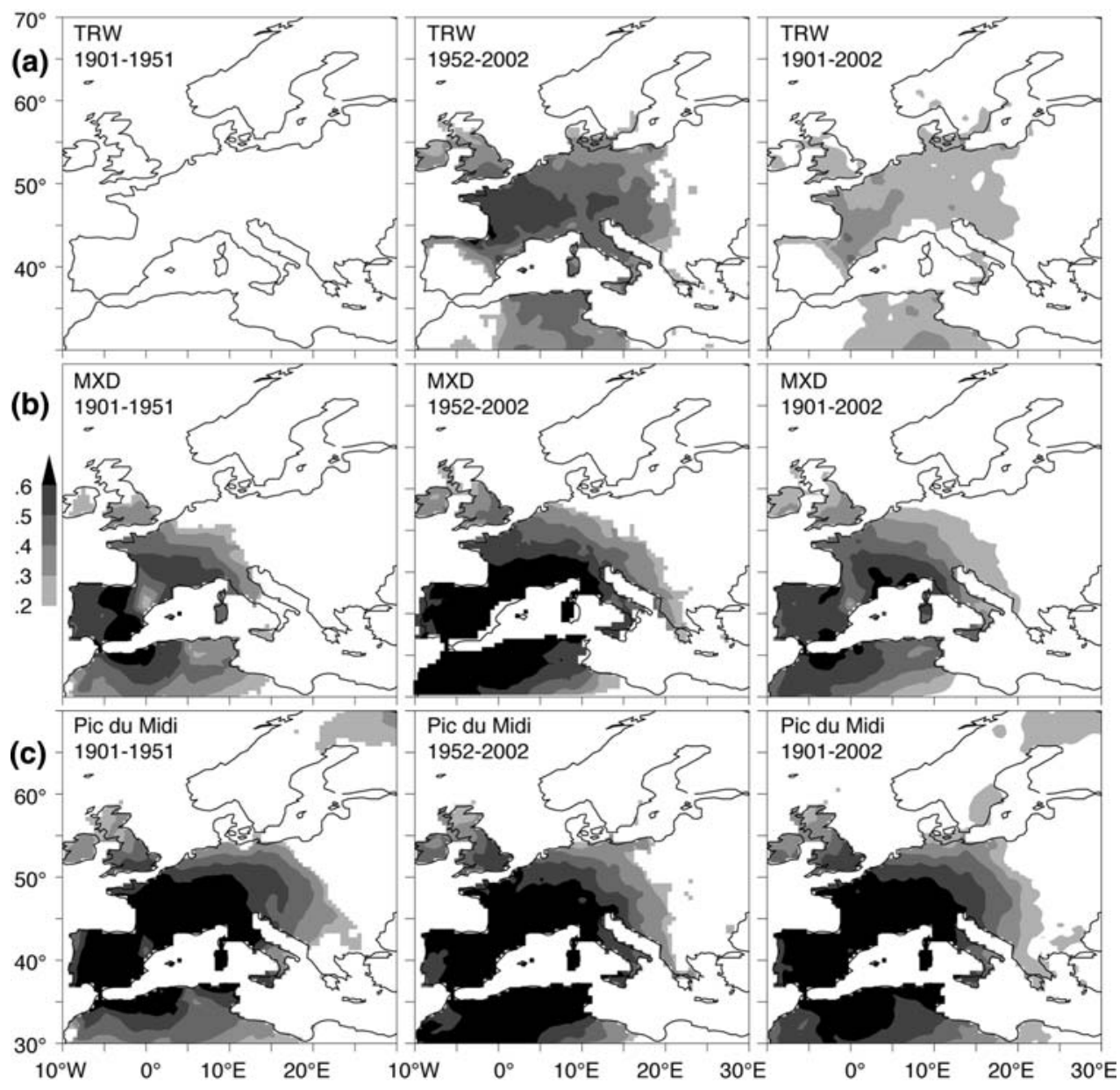

be invoked: the observed age trend in MXD might be related to (i) a systematic decrease in the ratio between cell wall size and lumen area with increasing tree age, or alternatively (ii) that the annual lignin content decreases with age. The first hypothesis presupposes that the amount of annual lignin content remains stable over time, and seems to be supported by the lack of correlation between the lignin content of latewood cells and measured MXD values (Gindl et al. 2000).

In line with distinct carry-over effects on earlywood cell formation (e.g., Fritts 1976), the TRW time-series retain more low-frequency variability than the MXD data, which show more inter-annual variability. In other words, TRW integrates effects from previous year climatic and ecological conditions, which leads to different signal-tonoise ratios on inter-annual versus multi-decadal timescales (e.g., Frank et al. 2007a). Such physiological induced autocorrelation reflects the utilization of abundant carbohydrates stored towards the end or even after the growing season (Kozlowski and Pallardy 1997). Carry-over processes can be obscured by longer-term gain (loss) in activating resources from root and needle growth following favorable (severe) conditions. Recent findings on carbon allocation of the evergreen conifer species Pinus uncinata suggest utilization of a considerable amount $(42 \%)$ of carbohydrate storage from the previous year for new wood formation, i.e., shoot and twig growth, whereas current-year rates of photosynthesis are of minor importance (Felten von et al. 2007). Parameter-specific differences in carry-over effects are also reported from conifer networks across the highnorthern latitudes (Briffa et al. 2002), the European Alps (Frank and Esper 2005), and western Carpathian arc (Büntgen et al. 2007a). Nevertheless, their causes are not fully understood and call for more efforts towards a better understanding of the timing of carbon allocation based on tracer studies (Kagawa et al. 2006). The coexistence of both TRW and MXD measurements may allows physiologically versus climate-induced persistence in cell development and enlargement to be separated Kirdyanov et al. 2007).

\section{Climate sensitivity}

We found the relationship between TRW and summer temperatures to be weak and instable over time. A similar 
weak climatic signal is reported for high-elevation TRW by Tardif et al. (2003), who analyzed inter-annual relationships between radial growth variations and temperature fluctuations for several (near timberline) Pinus uncinata sites within the Central Spanish Pyrenees. The herein observed differences in the degree of parameter-specific carry-over effects additionally stress a decline in climate sensitivity of TRW after severe conditions. This is most evident when trees have not fully recovered from external impacts (e.g., climate, insect outbreaks) and utilize carbohydrate reserves for purposes other than radial expansion; cell wall thickening during the second half of the vegetation period, however, is less affected (Frank et al. 2007a). While such differences are most pronounced during and after decadal-scale depressions in warm season temperatures (such as the prominent cooling during the early 19th century, Büntgen et al. 2008a), general features of TRW sensitivity to climate variability are likely also applicable during less harsh episodes with additional effects on interannual time-scales.

Conversely, our analyses confirmed a strong relationship between MXD and May-September temperatures across the network. This climatic fingerprint is most likely related to the timing of secondary cell wall formation (Gindl et al. 2000). A significant correlation between tracheid wall thickness and the duration of tracheid maturation (lignification) indicates continuous and quasi steady-state rates of cell wall formation within growth and differentiation zones. An increase in radial growth yields larger lumen and thus a decline in measured density. During the first part of the growing season, climatic variations affect radial enlargement, whereas during the later part of the growing season, climatic variations only affect the cell wall thickening process. More detailed information on specific correlations with climate of numerous tree-ring parameters (i.e., early and latewood width, and density) from high-elevation conifers in the Pyrenees can be found in Büntgen et al. (2007b). Distinct characteristics of MXD data, such as strong correlations with temperature during the early and late vegetation period but weaker correlations in-between, are further reported from a high-elevation larch network in the Swiss Alps (Büntgen et al. 2006), from a multi-species network across the Alps (Frank and Esper 2005), and from hundreds of sites scattered along the northern latitudinal timberline (Briffa et al. 2002). A recent study along the northern timberline in Eurasia by Kirdyanov et al. (2007) highlighted offset in the timing of the initiation of cambial activity and of rapid cambial cell division at the beginning of the vegetation period, and the enlargement of latewood tracheids and the thickening of their walls towards the end of the vegetation period. More precise knowledge on the intra-annual timing of stem growth, i.e., the onset of cambial activity, the duration and ending of cell differentiation, radial enlargement (TRW), wall thickening, and lignification (MXD) can be derived from high-resolution dendrometer and punching approaches (Moser et al. in press). Detailed experiments showed that maximum tracheid production corresponded to maximum day length, thus allowing cell wall formation and lignification to be completed independently by the end of summer (Rossi et al. 2006b). Determination of the onset of cambial activity, the duration and ending of cell differentiation, radial enlargement, wall thickening, and lignification has been assessed for high-elevation conifers (Rossi et al. 2007), indicating that the formation of thicker cell walls (relative to lumen size) in latewood tracheids is related to duration length (Rossi et al. 2006a). Gricar et al. (2005) related high correlations between MXD and late summer temperature to the lignification process of latest formed tracheids extending long after cambial cell division has ceased.

Besides those differences in climate sensitivity of TRW and MXD that are mainly related to physiological processes, differences in the relationship with regional temperature variability might be caused by changing climate and/or environmental conditions (Carrer and Urbinati 2006; Andreu et al. 2007). While MXD time-series reveal stable correlations with warm season temperature over the twentieth century and western Mediterranean basin, our network suggests deviation of TRW from the principle of uniformitarianism (Fritts 1976). Interestingly, the relationship between TRW and May-September temperature variability vanished back in time, considering some bias possibly emerging from the extended seasonal window, which is optimized to match the climate sensitivity of MXD. This TRW related backward decline in sensitivity-the loss of temperature sensitivity is not compensated by increasing precipitation or drought response-contradicts the observed 20 th century warming, and refutes underlying mechanisms of threshold-induced drought stress. Indication for a recent reduction in growth response to rising temperatures as reported from Alaska (Barber et al. 2000; Wilmking et al. 2004, 2005) is also not observed. Nevertheless, caution is advised, as the correlation between TRW and warm season temperature during the second part of the 20th century might be inflated by similar positive trends in both time-series (Büntgen et al. 2008b). Additional bias might emerge from a general underestimation of precipitation in higher elevation environments, and particularly the Mediterranean area where synoptic modes and topography complicate instrumental readings (Gao and Giorgi 2008). At this stage, we are unable to link the observed instability in climate sensitivity of TRW with plausible physiological and physical factors. 


\section{Conclusions}

A network of 49 conifer TRW and MXD chronologies from the Pyrenees allowed parameter-specific climate sensitivity to be assessed over the 20th century. Correlations with summer temperatures indicated sensitivity for MXD, but less spatiotemporal stability for TRW. Other controls on the network's growth/climate relationship that are possibly related to (i) climatic changes along the west-east gradient from the Atlantic Ocean to the Mediterranean Sea, (ii) differences in temperature means, precipitation totals and sunshine duration along the altitudinal gradient from the montane to sub-alpine forest zones, and (iii) physiological peculiarities of the three conifer species, have been shown to be insignificant for MXD. The formation of TRW, however, was found to be more responsive to a mixture of internal (biotic) and external (abiotic) factors besides summer temperature alone. Additional tree-ring parameters, such as isotopic composition might be helpful when estimating past Mediterranean climate variability.

Acknowledgments R. Wilson, A. Verstege, and F. Anders assisted fieldwork. F. Schweingruber and other ITRDB contributors provided tree-ring data. The NP d'Aigüestortes I Estany de Sant Maurici (namely J. V. Canillas) kindly provided sampling permission. Spatial field correlations were generated using the KNMI Climate Explorer (http://climexp.knmi.nl). Supported by the SNF project NCCRClimate (Extract) and the EU project MILLENNIUM (\#017008).

\section{References}

Andreu L, Gutiérrez E, Macias M, Ribas M, Bosch O, Camarero JJ (2007) Climate increases regional tree-growth variability in Iberian pine forests. Glob Change Biol 13:804-815

Barber V, Juday G, Finney B (2000) Reduced growth of Alaska white spruce in the twentieth century from temperature-induced drought stress. Nature 405:668-672

Briffa KR, Osborn TJ, Schweingruber FH, Jones PD, Shiyatov SG, Vaganov EA (2002) Tree-ring width and density around the Northern Hemisphere: Part 1, local and regional climate signals. Holocene 12:737-757

Büntgen U, Frank DC, Nievergelt D, Esper J (2006) Summer temperature variations in the European Alps, AD 755-2004. J Clim 19:5606-5623

Büntgen U, Frank DC, Kaczka RJ, Verstege A, Zwijacz-Kozica T, Esper J (2007a) Growth/climate response of a multi-species treering network in the Western Carpathian Tatra Mountains, Poland and Slovakia. Tree Physiol 27:689-702

Büntgen U, Frank DC, Verstege A, Nievergelt D, Esper J (2007b) Climatic response of multiple tree-ring parameters from the Central Spanish Pyrenees. Trace 5:60-72

Büntgen U, Frank DC, Grudd H, Esper J (2008a) Long-term summer temperature variations in the Pyrenees. Clim Dyn 31:615-631

Büntgen U, Frank DC, Wilson R, Carrer M, Urbinati C, Esper J (2008b) Testing for tree-ring divergence in the European Alps. Glob Change Biol 14:2443-2453

Camarero JJ, Gutiérrez E (2004) Pace and pattern of recent treeline dynamics: response of ecotones to climatic variability in the Spanish Pyrenees. Clim Change 63:181-200
Camarero JJ, Guerrero-Campo J, Gutiérrez E (1998) Tree-ring growth and structure of Pinus uncinata and Pinus sylvestris in the Central Spanish Pyrenees. Arctic Alpine Res 30:1-10

Camarero JJ, Gutiérrez E, Fortin MJ, Ribbens E (2005) Spatial patterns of tree recruitment in a relict population of Pinus uncinata: forest expansion through stratified diffusion. J Biogeogr 32:1979-1992

Carrer M, Urbinati M (2006) Long-term change in the sensitivity of tree-ring growth to climate forcing in Larix decidua. New Phytol 170:861-872

Cook ER, Peters K (1981) The smoothing spline: A new approach to standardizing forest interior tree-ring width series for dendroclimatic studies. Tree-Ring Bull 41:45-53

Cook ER, Peters K (1997) Calculating unbiased tree-ring indices for the study of climatic and environmental change. The Holocene 7:359-368

Cook ER, Briffa KR, Meko DM, Graybill DA, Funkhouser G (1995) The 'segment length curse' in long tree-ring chronology development for palaeoclimatic studies. Holocene 5:229-237

Eschbach W, Nogler P, Schär E, Schweingruber FH (1995) Technical advances in the radiodensitometrical determination of wood density. Dendrochronologia 13:155-168

Esper J, Cook ER, Krusic PJ, Peters K, Schweingruber FH (2003) Tests of the RCS method for preserving low-frequency variability in long tree-ring chronologies. Tree-Ring Res 59:81-98

Felten von S, Hättenschwiler S, Saurer M, Siegwolf R (2007) Carbon allocation in shoots of alpine treeline conifers in a $\mathrm{CO} 2$ enriched environment. Trees 21:283-294

Frank D, Esper J (2005) Characterization and climate response patterns of a high elevation, multi species tree-ring network for the European Alps. Dendrochronologia 22:107-121

Frank D, Büntgen U, Böhm R, Maugeri M, Esper J (2007a) Warmer early instrumental measurements versus colder reconstructed temperatures: shooting at a moving target. Quat Sci Rev 26:3298-3310

Frank D, Esper J, Cook ER (2007b) Adjustment for proxy number and coherence in a large-scale temperature reconstruction. Geophys Res Lett 34. doi:10.1029/2007GL030571

Fritts HC (1976) Tree rings and climate. Academic Press, London

Gao XJ, Giorgi F (2008) Increased aridity in the Mediterranean region under greenhouse gas forcing estimated from high-resolution simulations with a regional climate model. Glob Plan Change 62:195-209

Gindl W, Grabner M, Wimmer R (2000) The influence of temperature on latewood lignin content in treeline Norway spruce compared with maximum density and ring width. Trees 14:409-414

Giorgi F (2006) Climate change hot-spots. Geophys Res Lett 33. doi: 10.1029/2006GL025734

Gricar J, Cufar K, Oven P, Schmitt U (2005) Differentiation of terminal latewood tracheids in silver fir during autumn. Ann Bot 95:959-965

Kagawa A, Sugimoto A, Maximov T (2006) Seasonal course of translocation, storage and remobilization of $13 \mathrm{C}$ pulse-labeled photoassimilate in naturally growing Larix gmelinii saplings. New Phytol 171:793-804

Kirdyanov A, Vaganov EA, Hughes MK (2007) Separating the climatic signal from tree-ring width and maximum latewood density records. Trees 21:37-44

Kozlowski TT, Pallardy SG (1997) Growth control in woody plants. Academic Press, San Diego

Luckman BH, Wilson RJS (2005) Summer temperatures in the Canadian Rockies during the last millennium: a revised record. Clim Dyn 24:131-144

Mitchell TD, Jones PD (2005) An improved method of constructing a database of monthly climate observations and associated highresolution grids. Int J Climatol 25:693-712 
Moser L, Fonti P, Büntgen U, Franzen J, Esper J, Luterbacher J, Frank $\mathrm{D}$ (in press) Timing and duration of European larch growing season along altitudinal gradients in the Swiss Alps. Tree Physiol

Richman MB (1986) Rotation of principal components. J Clim 6:293-335

Rolland C, Schueller F (1994) Relationships between mountain pine and climate in the French Pyrenees (Font-Romeu) studied using the radiodensitometrical method. Pirineos 144:55-70

Rossi S, Deslauriers A, Anfodillo T (2006a) Assessment of cambial activity and xylogenesis by microsampling tree species: an example at the alpine timberline. Iawa 27:383-394

Rossi S, Deslauriers A, Anfodillo T, Morin H, Saracino A, Motta R, Borghetti M (2006b) Conifers in cold environments synchronize maximum growth rate of tree-ring formation with day length. New Phytol 170:301-310

Rossi S, Deslauriers A, Anfodillo T, Carraro V (2007) Evidence of threshold temperatures for xylogenesis in conifers at high altitudes. Oecologia 152:1-12

Ruiz-Flaño P (1988) Dendroclimatic series of Pinus uncinata R. in the Central Pyrenees and in the Iberian System. A comparative study. Pirineos 132:49-64

Schweingruber FH (1985) Dendro-ecological zones in the coniferous forest of Europe. Dendrochronologia 3:67-75

Schweingruber FH, Fritts HC, Bräker OU, Drew LG, Schär E (1978) The X-ray technique as applied to dendrochronology. Tree-Ring Bull 38:61-91

Stokes MA, Smiley TL (1968) An introduction to tree-ring dating. University of Chicago, Chicago, Reprinted 1996. University of Arizona Press, Tucson, US
Szeicz JM, MacDonald GM (1995) Dendroclimatic Reconstruction of Summer Temperatures in Northwestern Canada Since A.D. 1638 based on Age Dependent Modelling. Q Res 44:257-266

Tardif J, Camarero JJ, Ribas M, Gutiérrez E (2003) Spatiotemporal variability in tree growth in the Central Pyrenees: climatic and site influences. Ecol Mono 73:241-257

van der Schrier G, Briffa KR, Jones PD, Osborn TJ (2006) Summer moisture variability across Europe. J Clim 19:2818-2834

Wang L, Payette S, Bégin Y (2001) 1300-year tree-ring width and density series based on living, dead and subfossil black spruce at tree-line in Subarctic Québec, Canada. Holocene 11:333-341

Wiegand T, Camarero JJ, Rüger N, Gutiérrez E (2006) Abrupt population changes in treeline ecotones along smooth gradients. J Ecol 94:880-892

Wigley TML, Briffa KR, Jones PD (1984) On the average of value of correlated time series, with applications in dendroclimatology and hydrometeorology. J Clim Appl Meteorol 23:201-213

Wilmking M, Juday G, Barber V, Zald H (2004) Recent climate warming forces contrasting growth responses of white spruce at treeline in Alaska through temperature thresholds. Glob Change Biol 10:1724-1736

Wilmking M, D'Arrigo R, Jacoby G, Juday G (2005) Divergent growth responses in circumpolar boreal forests. Geophys Res Lett 32:L15715. doi:10.1029/2005GL023331

Wilson RJS, D'Arrigo R, Buckley B, Büntgen U, Esper J, Frank D, Luckman B, Payette S, Vose R, Youngblut D (2007) A matter of divergence: Tracking recent warming at hemispheric scales using tree-ring data. J Geophys Res 11. doi:10.1029/2006JD008318 